\title{
City Engagement in the Joint Programming Initiative Urban Europe and the Role of Intermediary Organizations in R\&I Policies for Urban Transition
}

\section{Susanne Meyer and Robert Hawlik}

\begin{abstract}
This research investigates the case of the Joint Programming Initiative (JPI) Urban Europe and its role as an intermediary organization, developing research, and innovation programs for urban transition. In the literature, the role of an intermediary organization has recently been discussed as an effective promoter and developer of connecting visions, strategies, activities, and stakeholders. A conceptual approach to intermediary organizations for urban transition is operationalized, and its functions are discussed in this paper. As an example, the Joint Programming Initiative Urban Europe reveals how a transnational R\&I initiative, represented by 20 national R\&I programs in Europe, can provide scientific evidence for sustainable urbanization with a cross-sectoral, integrated, inter- and transdisciplinary approach implemented through activities beyond joint calls. The findings show that JPI Urban Europe acts as broker and facilitator of joint visions and starts to build communities for innovation, which is one of the important functions of intermediaries. The development of its Strategic Research and Innovation Agenda clearly followed a co-creation process, putting the dilemmas of city practitioners in the center. JPI Urban Europe managed to attract high levels of commitment from a diversity of stakeholders to its strategic priorities and mobilized respective budgets for its implementation. The analysis of JPI Urban Europe participation in funded projects shows that challenge-driven calls (putting the problem owners in the center) seems to successfully develop a common language for all stakeholders and has a higher likelihood to generate more transformative outcomes. The number of funded urban living labs in projects shows that room for experimentation in niches and their extension is provided. The number of city representatives as funded project partners could be increased to further stimulate active involvement. The JPI Urban Europe also acts as a translator and enabler for learning in the urban-as well as in the policy sphere-the third function. This can be confirmed by the number and type of organizations reached with its specific formats. JPI Urban Europe coordinates joint activities of mainly national R\&I programs but has only
\end{abstract}

\footnotetext{
S. Meyer $(\varangle) \cdot$ R. Hawlik $(\bowtie)$

AIT Austrian Institute of Technology, Giefinggasse 4, 1210 Vienna, Austria

e-mail: Susanne.meyer@ait.ac.at

R. Hawlik

e-mail: Robert.hawlik@ait.ac.at
} 
indirect influence on change in these organizations and limited influence on changes within research organizations, businesses, or cities that are even less connected. Overall, it can be concluded that the strategic ambition of JPI Urban Europe towards transformative change is obvious, but some instruments and formats to translate the ambition into action need further refinement, and it needs further in-depth research to better understand the outcomes and impacts of its diverse activities.

Keywords City engagement $\cdot$ Transition pathways $\cdot$ R\&I policy making $\cdot$ Challenge-driven

\section{Introduction}

The transition of urban systems is central to a sustainable and resilient future as urbanization megatrends continue to persist, and principal global problems can only be addressed by system change in the urban area (Wolfram et al. 2019). An indication of the urgency of urban transition is the high-level policies that recently address this topic, e.g., the United Nation SDG (No 11 is dedicated to cities, UN 2019), the Paris Agreement with cities addresses as central players to fulfil the national climate goals or the EU Urban Agenda). But urban transition calls for an open, complex, self-organizing, adaptive and evolving systems, such as cities that need boundary-spanning collaboration, trust building, goal coordination and knowledge co-production (World Climate Research Programme 2019). Cities as problem owners should play a key role as they are both transition agents and subjects of transformation.

Wolfram et al. (2019) argue that deficits of effective intermediation are widespread, and the intermediation gap needs a dedicated response for urban transition. In the literature, the role of intermediary organization has recently been discussed as an effective promoter and developer of connecting visions, strategies, activities, and stakeholders. This research investigates empirically whether the Joint Programming Initiative (JPI) Urban Europe takes the role of an intermediary in sustainable transition, especially highlighting its role for R\&I policies, governance, engagement, and collective action towards urban transition. The JPI Urban Europe is a transnational R\&I programing initiative of 20 active European countries aiming to drive research and innovation for urban transitions and provide scientific evidence for sustainable urbanization with a cross-sectoral, integrated, inter- and transdisciplinary approach implemented through activities beyond joint calls (JPI Urban Europe 2015). The study addresses the following research questions: (1) What is the role of intermediary organizations for sustainable transition; (2) is JPI Urban Europe as a transnational R\&I program of 20 countries an intermediate organization for urban transition; and (3) are cities successfully engaged in this program as problem owners and change agents? To answer these questions, the paper is structured as follows. Section 2 introduces a conceptual approach on intermediary organizations for urban transition. Section 3 operationalizes the concept and outlines the functions of intermediaries like the JPI Urban Europe. Section 4 presents the methods used 
to investigate the intermediating role of JPI Urban Europe. Section 5 reports the respective results, and in Sect. 6 a discussion and concluding remarks take place.

\section{Intermediaries for Urban Transition-A Conceptual Basis}

The transition of urban systems is central to a sustainable and resilient future (Wolfram et al. 2019). The sustainability challenge for cities is time sensitive regarding the need to address it (UN 2019). Clear commitment and targeted efforts are needed to achieve the system transition on a grand scale and immediate action by various actors in society. Innovation is pivotal to transform the socio-technical system in urban areas; however, delivering urban change that is transformative is still a challenge. The role of intermediary organizations to contribute to the delivery of urban transition seems to be key (Wolfram et al. 2019; Kivimaa et al. 2019b) because they can spread niche innovation to a broader scale. In this conceptual part, firstly the multi-level-perspective on transition of socio-technical systems will be discussed, revealing how system change takes place and, secondly, the role and function of intermediary organizations for systems will be introduced. This forms the basis to discuss the role of JPI Urban Europe as a transnational intermediary organization and its ability to mobilize cities for change in the empirical part.

\subsection{Socio-technical Transition-A Multi-level-Perspective}

The urban system is a socio-technical system. Socio-technical systems are systems in which technological elements (e.g., physical infrastructure) and social elements (e.g., governance arrangements) are deeply intertwined. The socio-technical systems perspective highlights that both dimensions evolve together to address specific societal needs, such as mobility, sanitation, and energy (De Haan et al. 2014). A transition of socio-technical systems in cities is needed to address the sustainability challenge for cities.

Social technical landscapes embed both niches and regimes. Regimes represent highly stable and entrenched configurations of the underlying rules and routines that determine how things are being done in socio-technical systems (Fuenfschilling and Truffer 2016). Niches refer to spaces in which radical innovations emerge that fundamentally challenge the status quo. They are conceptualized as a protective space offering 'seeding' conditions for innovative practices (Kemp et al. 1998). The multi-level perspective argues that transitions come about through interactions between three levels: landscapes, regimes, and niches. Changes in the socio-technical landscape can be achieved through the processes of learning by experimentation new socio-technical solutions/configurations occurring in niches. Innovation occurring 
within niches needs to be extended to change the regime. Changes on the landscape level create pressure on the regime and opens windows of opportunity for niche innovation (Geels and Schot 2007; Schot and Geels 2008).

Change is transformative, when dominant rule sets, visions, norms, routines, and capacities that underpin dominant practices in socio-technical systems are changed (Ghosh and Schot 2019; Schot and Kanger 2018). Such changes in fundamental rules will involve multiple stakeholders.

\subsection{Role of Intermediary Organizations for Systemic Change Processes}

Various scholars have shown that changes for socio-technical transitions can be triggered and accelerated through intermediary organizations as part of the sustainability transition policies orchestrating a network of diverse actors, activities and resources and create momentum for change (Kivimaa et al. 2019b). Intermediary organizations can intermediate between innovative practices in niches and dominant practices in socio-technical regimes (Kivimaa et al. 2019b). Such organizations are particularly important in transformative change processes because system change is a multi-actor and multi-scale process that requires strong intermediary action (Fischer and Newig 2016). As such, intermediary actors are consistently described in the transformative change literature as important and active agents of change (Fischer and Newig 2016; Hodson and Marvin 2010; Kivimaa et al. 2019b). For urban transition, Wolfram et al. (2019) explicitly call for a stronger role of intermediaries to close the intermediation gap.

Kivimaa et al. (2019b) developed a typology of intermediary organizations including five types:

- A system intermediary promotes an explicit transition agenda and taking the lead in aiming for change on the whole system level.

- A regime-based transition intermediary is tied through institutional arrangements to the prevailing the socio-technical regime.

- A niche intermediary works to experiment and advance activities in niches.

- The process intermediary facilitates a change process often without a specific agenda but in context of priorities set by actors.

- A user intermediary translating new niche technologies to users and user preferences to developers and regime actors.

Many intermediaries are likely to tap into more than one type. Moreover, intermediaries act on different phases of levels of transition (Kivimaa et al. 2019a). 


\section{Functions of System Intermediaries for Urban Transition}

JPI Urban Europe promotes urban transition through R\&I, and it can, therefore, be assumed that it mainly acts as system intermediary according to the typology of Kivimaa et al. (2019b). Recently, the intermediation gap in urban transition, as well as the main function of system intermediaries, has been outlined by multiple scholars (Kivimaa et al. 2019b; Klerkx and Leeuwis 2009; Geels and Deuten 2006; Wolfram et al. 2019; Hargreaves et al. 2013; Smith et al. 2016; Hodson and Marvin 2012). The three main functions of system intermediaries can be summarized as follows to answer research question 1 :

\section{Broker and facilitator of joint visions and communities for innovation}

- Connecting and coordinating between multiple stakeholders and their priorities, strategic interests and knowledge pools, as well as creating and aligning those to facilitate transitions,

- Opening up space in the urban context for new and diverse kinds of activities,

- Connecting and integrating European, national and regional strategies and priorities, and

- Creating and exploring alternative governance structures.

2. Translator and enabler for learning

- Translating scientific knowledge for urban stakeholders,

- Articulating opinions and demand of cities and other urban stakeholders to the R\&I community, and

- Supporting learning processes of new urban stakeholder communities.

3. Provider for room for experimentation in niches and extend niches

- Mobilizing political and financial programs for urban innovation,

- Setting up experiments in niches, and

- Connecting local experimentations and global niches for transition by aggregating learnings and translating good practice and standards to influence new projects.

JPI Urban Europe could well function as a system intermediary organization for urban transition. One of the key challenges for an intermediary like the JPI Urban Europe is the mobilization of cities with a set of activities. The next empirical chapter will focus on the research questions 2 and 3 investigating whether JPI Urban Europe has attributes of an intermediary organization for urban transition and if it successfully mobilizes cities as problem owner to the program. 


\section{Method}

The research is based on primary and secondary data collection performed 20182019 in the course of program monitoring related tasks and a self-evaluation of the engagement of cities in the JPI Urban Europe (Meyer et al. 2018, 2019). The primary and secondary analysis methods will be described in the following while further details on the data can be found in the Appendix.

Secondary Data Analysis: The JPI Urban Europe has developed a project database which includes information on JPI Urban Europe funded projects from the first six calls (2012-2017). The list includes a total of 73 projects and 493 project partners based in 29 countries. Detailed information on the countries involved, as well as a map displaying the geolocation of the European project partners, is shown in the Appendix. An analysis of the cities involved in the projects has be conducted using this project database. Furthermore, a social network analysis was performed on the connections between project partners in funded projects.

Based on the list of participants in events of the JPI Urban Europe in the period 2017-2018, a database of JPI Urban Europe event participants (individual level) has been developed. The list includes events that have been open for cities and aid the analysis of stakeholder involvement in the JPI. In addition, a comparison of cities engaged in JPI Urban Europe projects and city participation in the EU Framework Programme based on the AIT-EUPRO database has been conducted to compare city participation in the two programs.

Primary Data Analysis: Semi-structured interviews with five (Limassol (CY), Ludwigsburg (DE), Almada (PT), Stockholm (SE), Southend-on-Sea (UK)) out of twelve pre-selected cities which were formal JPI Urban Europe project partners and three interviews with city experts have been conducted in winter 2018/2019 to learn from the cities perspectives what are the success factors for beneficial participation and what formats they recommend for engagement in JPI Urban Europe. The JPI UE project database (see Appendix) was used to identify cities from various countries.

Moreover, an online survey to the JPI Urban Europe Funding Agency Working Group was conducted to construct an overview of current funding and potential other support conditions for cities in the future. Responses from 20 agencies elicited across Europe were received. The survey targeted the types of entities that can be funded given the current involvement of the funding agency in JPI Urban Europe, the eligibility of city authorities/municipalities for funding and other opportunities to supporting city authorities.

\section{Results and Discussion}

This section answers research question 2-whether the JPI Urban Europe fulfills the function of an intermediary organization and research question 3-whether the JPI Urban Europe managed to engage cities as problem owners in the program. 
The following sections illustrates the findings from the primary and secondary data analysis in relation to research questions 2 and 3.

\subsection{Joint Vision and Research Agenda}

As a transnational R\&I programing initiative of 20 European countries (AT, BE, CH, CY, DE, DK, ES, FI, FR, IT, LV, NL, NO, PL, PT, RO, SL, SE, TR, UK), JPI Urban Europe follows a vision formulated as Strategic Research and Innovation Agenda (SRIA) in a co-creative process involving policy makers, researchers, city administration, city networks, societal actors, and research funders (JPI Urban Europe 2019a). The SRIA was developed over the course of an approximately oneyear-long process including an open consultation, stakeholder dialogue, and national consultations in member states, as well as input from researchers, other networks, and European policy actors.

The SRIA focusses on urban transition on a systemic level by aiming at impact on cities, national urban policies and R\&I policies. In its vision, JPI Urban Europe defined its ambition to support cities in their transition efforts and create robust evidence according to their needs. The SRIA follows a dilemma approach putting the conflict of interests and trade-offs between urban developments in the center because the hardest challenges for cities are reflected in trans-silo complex nexus issues. The JPI aims to explicitly address competing goals of multiple stakeholders, as well as urban governance as a cross-cutting concern. The dilemmas in the SRIA identify the need for integrating European, national and regional strategies and policies that the JPI aims to broker by creating knowledge and exchange interfaces. By targeting the stabilizing and destabilizing forces in regimes of socio-technical urban systems, the JPI Urban Europe assumes the role of a system intermediary.

Multiple instruments for implementing the SRIA focus on the connection and coordination between stakeholder types to match the priorities of urban practitioners. The Funding Agencies Working Group implements an annual Joint Call program focusing on a challenge-driven approach towards funding R\&I projects in the area of urban transition illustrated in Sect. 5.2. Furthermore, the stakeholder platform, AGORA, is designed as instrument to bring together, problem owners, industry, and research in a series of target-group specific events. Findings in relation to the platform are described in Sect. 5.3.

To conclude, with its co-creative and participatory process to develop a joint vision and a research strategy between all countries, cities and other stakeholders, the JPI Urban Europe could prove to fulfil the first function of an intermediary organizations as 'broker and facilitator of joint visions and communities for innovation.' The JPI Urban Europe managed to coordinate the interests and priorities of all participating countries and gained approval of a research agenda and a commitment for implementation. Meanwhile, $€ 50 \mathrm{M}$ were invested in the implementation of the research agenda and over 70 projects funded. JPI Urban Europe does not only manage to coordinate national strategy and interests on a high level, but also on an operational 
level when it comes to the management and monitoring of joint calls and projects of the countries. Additionally, JPI Urban Europe managed to open up space for new R\&I actors - namely cities. Cities have not only been engaged in the development of the research agenda, but have been empowered by their needs being put at the center.

\subsection{City Engagement in Projects and Local Experimentation}

The series of annual R\&I calls is one of the most important instruments addressing and engaging cities as problem owners in the urban transition. However, only 22 cities out of 445 funded project partners have been involved in JPI Urban Europe projects in the first six calls. The engagement of city representatives as project partners varies by call format as shown in Table 1 . While less than one in ten project partners were city representatives in the first five R\&I calls, the sixth call was specifically designed to engage a high share of cities by funding challenge-driven innovation projects and requiring consortia to include at least one business and one city partner. Thus, it aimed to support new structures in the funded projects putting the problem owners in the center and fostering bidirectional learning between the cities and other R\&I partners. The total number of cities with granted funding was, nevertheless, low as the call included a small number of participating funding agencies and allocated national budgets.

A collaboration analysis of funded projects highlights the role of JPI Urban Europe in connecting multiple stakeholder types. Figure 1 displays the collaborations between city representatives and other actor type groups in a collaboration network of funded projects. Nodes represent actor types in a given country collaborating with other actors via joint projects. While universities take up central roles in the network - three out of four projects are led by universities - cities are less frequently represented in the network. Interviews revealed that cities take roles as data and feedback providers, providers of specific non-research expertise, and test beds for

Table 1 Cities with granted funding in the first six JPI Urban Europe Joint Calls

\begin{tabular}{l|l|l|l|l}
\hline & Project running time & Project partners & Cities (funded) & $\%$ of total \\
\hline Call VI & $2019-2022$ & 42 & 6 & 14 \\
\hline Call V & $2018-2021$ & 135 & 4 & 3 \\
\hline Call IV & $2017-2020$ & 84 & 2 & 2 \\
\hline Call III & $2016-2019$ & 100 & 6 & 6 \\
\hline Call II & $2014-2017$ & 47 & 1 & 2 \\
\hline Call I & $2013-2016$ & 37 & 3 & 8 \\
\hline Total & & 445 & 22 & 5 \\
\hline
\end{tabular}

Source Own calculations based on the JPI Urban Europe Project Database 


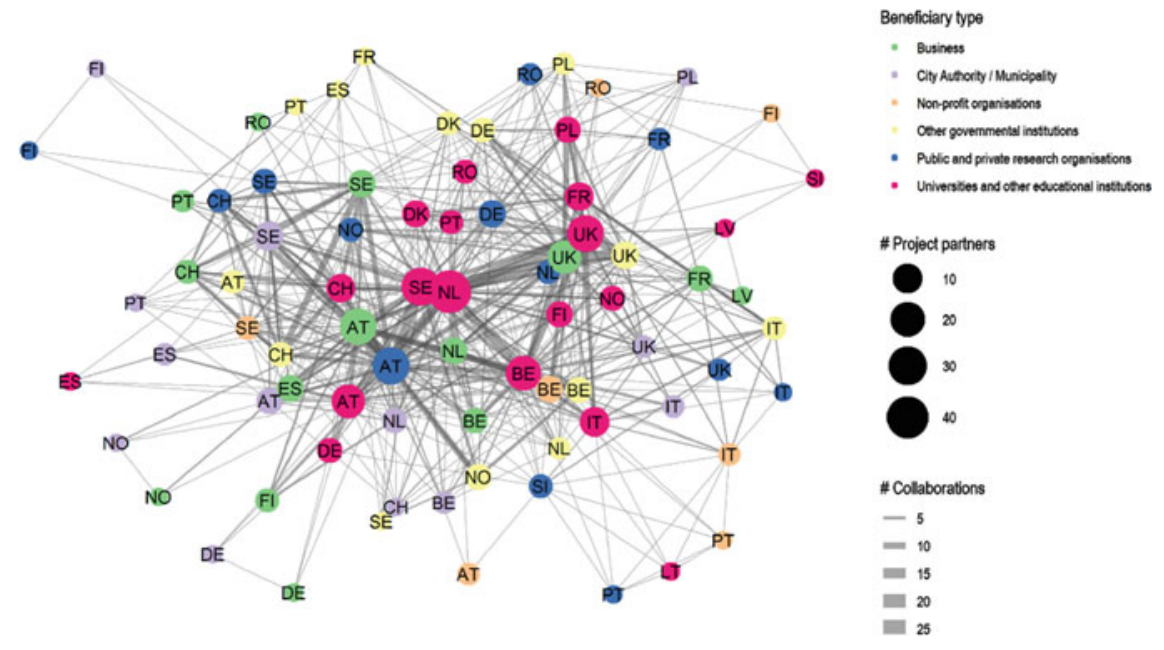

Fig. 1 Collaboration network based on JPI Urban Europe project partners by country and actor type. The network position is based on the frequency of cooperation between project partners in various countries (country code labels, ISO 3166-2) and the project partner type (color). Node size shows the number of project partners of the type in the country, while the edge width depicts the number of joint projects. Source Own calculations based on the JPI Urban Europe Project Database

piloting project outputs. University-business cooperation is the most frequent type of transdisciplinary collaboration.

A geographic distribution of cities in projects shows that one out of four cities that are project partners in Joint Calls is located in Sweden as shown in Table 3. The survey to all JPI Urban Europe funding agencies revealed that cities are eligible only for funding in $45 \%$ of the funding agencies; however, the interviews with cities clearly indicated how important funding for cities is to engage in R\&I projects. This enhances cities internal justification for participation and made engagement more effective by increasing the city's feeling as 'problem owners.'

Out of the 20 JPI Urban Europe cities involved in projects, five cities are also active in $\mathrm{H} 2020$ projects, whereas 15 (75\%) cities are not active in any $\mathrm{H} 2020$ projects dedicated to sustainable urbanization. JPI Urban Europe attracts new cities for projects at the European/transnational level and therefore works complementarily to H2020. Moreover, JPI Urban Europe calls tend to mobilize smaller cities than H2020 calls, hinting at its role as a provider of room for experimentation in niches and extending niches (Table 2).

Formats that allow less experienced and often smaller cities to connect to successful networks and consortia can be seen as a strength of JPI Urban Europe. City interviews reveal that the classical call structure of JPI Urban Europe represents a high barrier to entry for both experienced and inexperienced cities. In this regard, the city interviews found that additional formats, such as structured exchange and mutual learning processes between cities and/or between cities and academia/business, could lower the entry barriers. 
Table 2 City characteristics in H2020 and JPI Urban Europe projects

\begin{tabular}{l|l|l|l|l|l|l}
\hline & \multicolumn{5}{l}{ H2020 } & \multicolumn{2}{l}{ JPI Urban Europe } \\
\hline Pop-class & $\begin{array}{l}\text { Total }(n= \\
128)\end{array}$ & Share $(\%)$ & $\begin{array}{l}\text { Cum. } \\
\text { share }(\%)\end{array}$ & $\begin{array}{l}\text { Total }(n= \\
20)\end{array}$ & Share $\%)$ & $\begin{array}{l}\text { Cum. } \\
\text { share }(\%)\end{array}$ \\
\hline$<50,000$ & 12 & 9 & 9 & 3 & 15 & 15 \\
\hline $50,000-100,000$ & 20 & 16 & 25 & 2 & 10 & 25 \\
\hline $100,001-250,000$ & 28 & 22 & 47 & 7 & 35 & 60 \\
\hline $250.001-500,000$ & 25 & 20 & 66 & 3 & 15 & 75 \\
\hline $500.001-1 \mathrm{M}$ & 24 & 1 & 85 & 4 & 20 & 95 \\
\hline$>1 \mathrm{M}$ & 19 & 15 & 100 & 1 & 5 & 100 \\
\hline Total & 128 & 100 & & 20 & 100 & \\
\hline
\end{tabular}

Source Own calculations based on the JPI Urban Europe Project Database and AIT-EUPRO

Urban living labs represent an important means by which JPI Urban Europe provides room for experimentation in niches and extending niches. Nearly half of the 73 funded projects engage with urban living labs, i.e., arenas for experimentation, innovation and transformation, while providing test grounds in a real-world environment for urban transition (JPI Urban Europe 2018, 2019b). JPI Urban Europe follows recommendations highlighting the importance of experimentation and science-policy cooperation as one central requirement for addressing transition processes (Weber et al. 2018). Living labs not only serve the purpose of gaining experience and capacity building in cities, but also as a first step towards scaling-up responses in systems of provision (Marvin et al 2018). 'Learning journeys' including stories of success and failure are shared between and within various contexts to stimulate urban transitions. The survey to R\&I funding agencies, furthermore, revealed that funding living labs is an alternative way to support cities in cases where cities are not eligible for funding as project partners; three quarters of all surveyed funding agencies may support cities indirectly via urban living labs.

The empirical results on the funded joint projects prove that JPI Urban also fulfills the third function of an intermediary 'provider of room for experimentation in niches and extend niches.' The joint calls mobilizing the cooperation of national R\&I programs for urban transition and can address challenges that cannot be addressed by one country alone. The funded projects according to cities' needs, but especially the living labs provide concrete opportunities to experiment with products, services, tools, methods and processes to support the urban transition. Since the very beginning, JPI Urban Europe synthesized results from the projects and labs towards policy recommendation and policy action. It has established channels for dissemination across all participating countries. By this activity, JPI Urban Europe could prove that it not only provides innovation in niches, but also try to extent niches towards changes in the regime level.

The analysis of city engagement in the projects provides answers to research question 2. Although JPI Urban Europe manage to engage cities in the process of visioning 
and research agenda development, the actual number of cities that engaged as formal partner in projects is low. Many more cities have been engaged in the projects in other ways (via letter of intent, subcontract, expert). However, cities reported that that higher justification and the change effect are realized if they participate as formal partners. The main reason for the low number of partner cities in projects is that they are not eligible for funding in some R\&I program. In the future, JPI Urban Europe must ensure that the framework conditions to participate in the actions are available and attractive to various stakeholder types. This relates especially to cities as the core spaces of transition. Providing funding opportunities for cities is a key success factor for the JPI Urban Europe in fostering challenge-driven R\&I projects that meet cities' problems and increase the likelihood to produce transformative outcomes. However, JPI Urban Europe's activities also trigger changes of funding rules on national level, e.g., two funding agencies have made cities eligible for funding since the inception of the program. As JPI Urban Europe has its roots in national and regional R\&I funding agencies, the entry barrier for less experienced cities to take part in the action is lower than in European Framework Programme projects, which shows that the JPI Urban Europe functions as broker and translator also for smaller cities and reaches them.

\subsection{Knowledge Community on Urban Transition in Europe}

JPI Urban Europe aims to translate knowledge between various stakeholder communities and bring them together for mutual learning. On the one hand, the stakeholder communities represent urban communities of practice (e.g., urban research, citizen organizations, city authorities, business, public utility providers) and, on the other hand, they are policy communities of practice.

JPI Urban Europe has developed a Stakeholder Involvement Platform, namely AGORA, as an instrument to translate scientific knowledge for urban stakeholders, articulate opinions and demands of cities and other urban stakeholders to the R\&I community and support learning processes of new urban stakeholder communities. AGORA has been established to create a space to meet in interactive formats and exchange for all stakeholders, in particular, urban actors with a diversity of backgrounds (researchers, practitioners, public administrators, entrepreneurs, social innovators, etc.), discussing current themes and priorities and identifying the most pressing urban challenges of today and the future. Additionally, JPI Urban Europe has developed high-level policy conferences organized in Brussels where the policy community meets and engages.

An analysis of the participation of stakeholders, especially cities, in the respective events for the urban and policy communities reveals whether JPI Urban Europe has reached out to a wider community.

One hundred thirty three cities have participated in events organized by the JPI Urban Europe between 2014 and June 2018. Only events that were targeted and/or open to cities have been analyzed. The JPI Urban Europe Policy Conferences have mobilized the highest share of cities (15\%), followed by AGORA events (8\%). Of 
the 1281 participants, $10 \%$ of the total number of events have involved cities (city authorities, city agencies, regions, networks of cities within a region). Two AGORA events took place from 2017 to June 2018 having cities as target group.

The empirical results on community building revealed that JPI Urban Europe also fulfilled the second function of an intermediary 'translator and enabler for learning.' It brings together a diversity of stakeholders in interactive formats and enables learning, connecting and synthesizing of results. Within this stakeholder platform, a science-policy community on urban transition was built putting the cities as problem owners in the center. One main element was the establishment of a dialogue between researchers, urban stakeholders and policy makers in cities to generate a joint understanding of problems and common language.

The analysis of the strategic approach and activities of JPI Urban Europe could prove that it fulfills to a considerable extent all three functions of an intermediary organization outlined in Sect. 3. This answers research question 3.

\section{Conclusion}

The transition of urban systems is central to attaining a sustainable and resilient future. Cities as problem owners should play a key role as they are both transition agents and subjects of transformation. Deficits of effective intermediation of priorities, stakeholders, and activities at the European, national and local levels are widespread, and the intermediation gap needs a dedicated response for urban transition. The results of the empirical analysis have shown that transition-oriented R\&I programs of many countries, such as the JPI Urban Europe, can take this intermediating role and act as intermediary organizations. The case of the JPI Urban Europe could prove that it acts as effective promoter and developer of connecting visions, strategies, activities and stakeholders. JPI Urban Europe also has managed to attract high levels of commitment from a diversity of stakeholders to its vision and strategic priorities and mobilized respective budgets for its implementation. JPI Urban Europe opened spaces for cities as a central R\&I player to ensure that their needs become strategic priorities for the research agenda. Challenge-driven calls with room for experimentation (putting the problem owners at the center) seem to successfully develop a common language of all stakeholders and has a higher likelihood to generate more transformative outcomes. The involvement and empowerment of cities as problem owners is relevant for system transition. The number of city representatives as funded project partners could be increased to further stimulate active involvement because the eligibility of cities as project partners has been identified as a supporting factor. As an intermediary organization, JPI Urban Europe needs to work on this framework condition. This also calls for experimentation on the policy and program level as this is key to move urban transition forward. However, JPI Urban Europe can only stimulate these changes on the regime level, and it remains unknown what changes of behavior and organizations occur because of the engagement in the JPI Urban Europe. JPI Urban Europe coordinates joint activities of mainly national R\&I programs but 
has only indirect influence on change in these organizations and limited influence on changes within research organizations, businesses, or cities which are even less connected.

Overall, it can be concluded that: (1) The strategic ambition of JPI Urban Europe indicates a strong role of JPI Urban Europe as intermediary organization for urban transition, but some instruments and formats to bring the ambition into action need further refinement and experimentation, whereas other already work well; and (2) it needs further in-depth research to better understand the outcomes and impacts of its diverse activities.

\section{Appendix}

JPI Urban Europe has developed a project database which includes information on 73 funded projects from the first six calls (2012-2017) including a total of 493 project partners among which 445 received funding. The database includes the following information:

- Project name and respective call, call topic and Strategic Research and Innovation Agenda topic to which it is dedicated

- Project duration and research type

- Beneficiary names, country, types, and funding.

The structure of the project database allows for a social network analysis in which project partners are connected via projects.

Figure 2 shows the geographic location of 374 geocoded project partners colored by partner type. A country is colored light red if a funding agency based in the country participated in at least one R\&I call.

Table 3 provides further details on the countries involved in the JPI Urban Europe, the number of project partners and city representatives interviewed in the primary data analysis. In addition to 20 official member countries, five countries participate as observers without voting rights in the Governing Board. Further ten countries have funding agencies participating in Joint Calls without membership in the JPI Urban Europe. Out of the 445 funded project participants shown in the table, 22 were city authorities or municipalities. City representatives from five of the participating cities were interviewed in the course of a self-evaluation on the engagement of cities in the JPI Urban Europe (Meyer et al. 2018, 2019). 


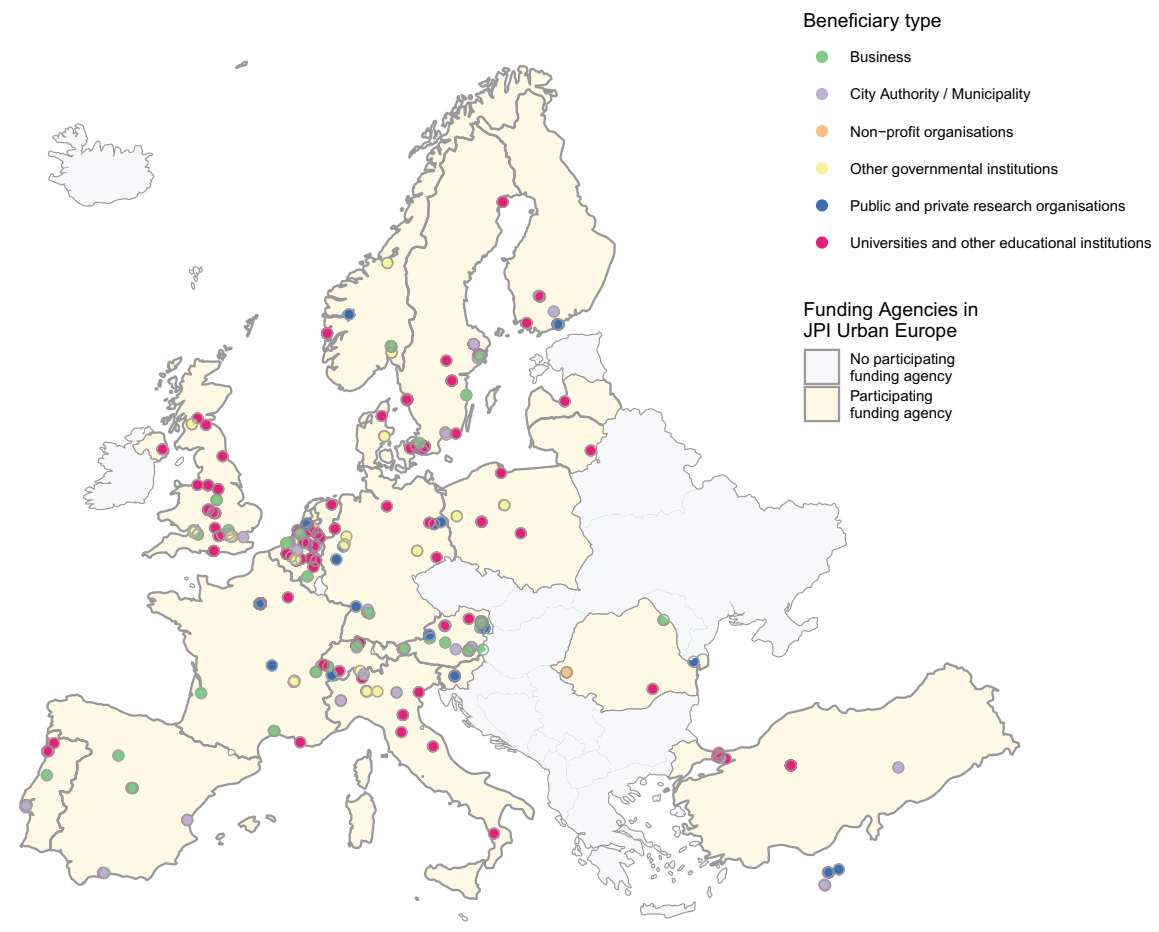

Fig. 2 Geocoded location of JPI Urban Europe project partners. Source Own calculations based on the JPI Urban Europe Project Database. Geolocation received via the Google Geocoding API 
Table 3 Countries involved in the JPI Urban Europe (Status 2019), the type of involvement (member, observer, participant in joint calls), the number of project partners based in the country, the number of city authorities/municipalities as official project partners and the interviews conducted)

\begin{tabular}{|c|c|c|c|c|}
\hline Country & $\begin{array}{l}\text { Level of } \\
\text { involvement }\end{array}$ & $\begin{array}{l}\text { Number of } \\
\text { project } \\
\text { participants }\end{array}$ & $\begin{array}{l}\text { Thereof City } \\
\text { Authority/Municipality }\end{array}$ & Interviews \\
\hline Argentina & Joint Call & 1 & & \\
\hline Australia & Joint Call & 1 & & \\
\hline Austria & Member & 78 & 5 & \\
\hline Belgium & Member & 33 & 1 & \\
\hline Brazil $^{\mathrm{a}}$ & Joint Call & 6 & & \\
\hline $\begin{array}{l}\text { Chinese } \\
\text { Taipei }\end{array}$ & Joint Call & 5 & & \\
\hline Cyprus & Member & 6 & 1 & Limassol \\
\hline Denmark & Member & 9 & & \\
\hline Finland & Member & 10 & 1 & \\
\hline France & Member & 14 & & \\
\hline Germany & Member & 16 & 1 & Ludwigsburg \\
\hline Italy & Member & 13 & 2 & \\
\hline Japan & Joint Call & 4 & & \\
\hline Latvia & Member & 2 & & \\
\hline Netherlands & Member & 45 & & \\
\hline Norway & Member & 14 & 1 & \\
\hline Poland & Observer & 8 & 1 & \\
\hline Portugal & Observer & 9 & 1 & Almada \\
\hline Qatar & Joint Call & 4 & & \\
\hline Romania & Observer & 7 & & \\
\hline Slovenia & Member & 4 & & \\
\hline South Africa & Joint Call & 6 & & \\
\hline Spain & Observer & 7 & & \\
\hline Sweden & Member & 47 & 6 & Stockholm \\
\hline Switzerland & Joint Call & 12 & & \\
\hline Turkey & Observer & 10 & & \\
\hline $\begin{array}{l}\text { United } \\
\text { Kingdom }\end{array}$ & Member & 53 & 1 & Southend-on-Sea \\
\hline USA & Joint Call & 21 & 1 & \\
\hline Total & & 445 & 22 & 5 \\
\hline
\end{tabular}

${ }^{\text {a São Paulo }}$

Source Own calculations based on the JPI Urban Europe Project Database and primary data analysis 


\section{References}

De Haan F, Ferguson BC, Adamowicz RC, Johnstone P, Brown RR, Wong THF (2014) The needs of society: a new understanding of transitions, sustainability and liveability. Technol Forecast Soc Change 85(2014): 121-132

Fischer LB, Newig J (2016) Importance of actors and agencies in sustainable transition: a systematic exploration of the literature. Sustainability 8(5):476

Fuenfschilling L, and Truffer B (2016) The interplay of institutions, actors and technologies in socio-technical systems - an analysis of transformations in the Australian urban water sector. Technol Forecast Soc Change 103(C):298-312

Geels F, Deuten J (2006) Local and global dynamics in technological development: a socio-cognitive perspective on knowledge flows and lessons from reinforced concrete. Sci Public Policy 33:265275

Geels FW, Schot J (2007) Typology of sociotechnical transition pathways. Res Policy 36:399-417

Ghosh B, Schot J (2019) Towards a novel regime change framework: studying mobility transitions in public transport regimes in an Indian megacity. Energy Res Soc Sci 51:82-95

Hargreaves T, Hielscher S, Seyfang G, Smith A (2013) Grassroots innovations in community energy: the role of intermediaries in niche development. Global Environ Change 23:868-880

Hodson M, Marvin S (2010) Can cities shape socio-technical transitions and how would we know if they were? Res Policy 39:477-485

Hodson M, Marvin S (2012) Mediating low-carbon urban transition? Forms of organization, knowledge and action. Eur Plan Stud 30(3):421-439

JPI Urban Europe (2015) Transition towards sustainable and liveable urban futures. Available at: https://jpi-urbaneurope.eu/app/uploads/2016/05/JPI-Urban-Europe-SRIA-Strategic-Res earch-and-Innovation-Agenda.pdf. Accessed 15 Jan 2020

JPI Urban Europe (2018). Urban Living Labs by JPI Urban Europe. Available at https://jpiurbaneurope.eu/app/uploads/2018/01/Urban-Living-Labs-info-sheet-draft-171123-version-8.2PRINT.pdf. Accessed 30 Jan 2020

JPI Urban Europe (2019a). Strategic research and innovation agenda 2.0. Available at https://jpiurbaneurope.eu/app/uploads/2019/02/SRIA2.0.pdf. Accessed 26 Jan 2020

JPI Urban Europe (2019b) JPI Urban Europe: the knowledge hub for urban transitions. Available at https://jpi-urbaneurope.eu/app/uploads/2019/09/Leaflet-JPI-UE-4P.pdf. Accessed 30 Jan 2020

Kemp R, Schot J, Hoogma R (1998) Regime shifts to sustainability through processes of Niche formation. The approach of strategic Niche management. Technol Anal Strategic Manag 10:175196

Kivimaa P, Boon W, Hyysalo S, Klerkx L (2019) Towards a typology of intermediaries in sustainability transitions: a systematic review and a research agenda. Res Policy 48(4):1062-1075

Kivimaa P, Hyysalo S, Boon W, Klerkx L, Martiskainen M, Schot J (2019) Passing the baton: how intermediaries advance sustainability transitions in different phases. Environ Innov Soc Transit $31: 110-125$

Klerkx L, Leeuwis C (2009) The emergence and embedding of innovation brokers at the different innovation system levels: insights from the Dutch agricultural sector. Technol Forecast Soc Change 76:849-860

Marvin S, Bulkeley H, Mai L, McCormick K, Voytenko Palgan Y (eds) (2018) Urban living labs: experimenting with city futures. Routledge, New York

Meyer S, Böhme K, Kalcik R (2018) Progress monitor JPI Urban Europe-findings of the pilot action on programme monitoring. EXPAND Support Deliver 7:2

Meyer S, Kalcik R, Wang A, Dinges M (2019) Self-evaluation report of the JPI Urban Europeengagement of cities in the JPI Urban Europe. EXPAND Deliver 7:3

Schot J, Kanger L (2018) Deep transitions: emergence, acceleration, stabilization and directionality. Res Policy 47(6): 1045-1059

Schot J, Geels FW (2008) Strategic niche management and sustainable innovation journeys: theory, findings, research agenda, and policy. Technol Anal Strategic Manag 20(5):537-554 
Smith A, Hargreaves T, Hielscher S, Martiskainen M, Seyfang G (2016) Making the most of community energies: three perspectives on grassroot innovation. Environm Plann A 48(2):407432

UN (2019) The sustainable development goals report 2019. Available at: https://unstats.un.org/sdgs/ report/2019/. Accessed 15 Jan 2020

Weber M, Andreescu L, Cuhls K, Dragomir , Gheorghiu, R., Giesecke, S., Ricci, A., Rosa, A., Shaper-Rinkel, P., and Sessa, C. (2018). Transitions on the Horizon: perspectives for the European Union's future research and innovation policies. BOHEMIA Final report. Available at https://ec. europa.eu/info/sites/info/files/transitions-on-the-horizon-2018_en.pdf. European Commission, Brussels. Accessed 30 Jan 2020

Wolfram M, Borgström S, Farrelly M (2019) Urban transformative capacity: from concept to practice. Ambio 48:437-448

World Climate Research Programme (2019) Global research and action agenda on cities and climate change science-full version (Prieur-Richard AH, Walsh B, Craig M, Melamed ML, Colbert M, Pathak M, Connors S, Bai X, Barau A, Bulkeley H, Cleugh H, Cohen M, Colenbrander S, Dodman D, Dhakal S, Dawson R, Espey J, Greenwalt J, Kurian P, Lee B, Leonardsen L, Masson-Delmotte V, Munshi D, Okem A, Delgado Ramos GC, Sanchez Rodriguez R, Roberts D, Rosenzweig C, Schultz S, Seto K, Solecki W, van Staden M, Ürge-Vorsatz D, eds). 31 pp. WCRP Publication No. 13/2019. Available at: https://www.wcrp-climate.org/WCRP-publications/2019/GRAA-Cit ies-and-Climate-Change-Science-Full.pdf

Open Access This chapter is licensed under the terms of the Creative Commons Attribution 4.0 International License (http://creativecommons.org/licenses/by/4.0/), which permits use, sharing, adaptation, distribution and reproduction in any medium or format, as long as you give appropriate credit to the original author(s) and the source, provide a link to the Creative Commons license and indicate if changes were made.

The images or other third party material in this chapter are included in the chapter's Creative Commons license, unless indicated otherwise in a credit line to the material. If material is not included in the chapter's Creative Commons license and your intended use is not permitted by statutory regulation or exceeds the permitted use, you will need to obtain permission directly from the copyright holder.

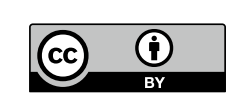

